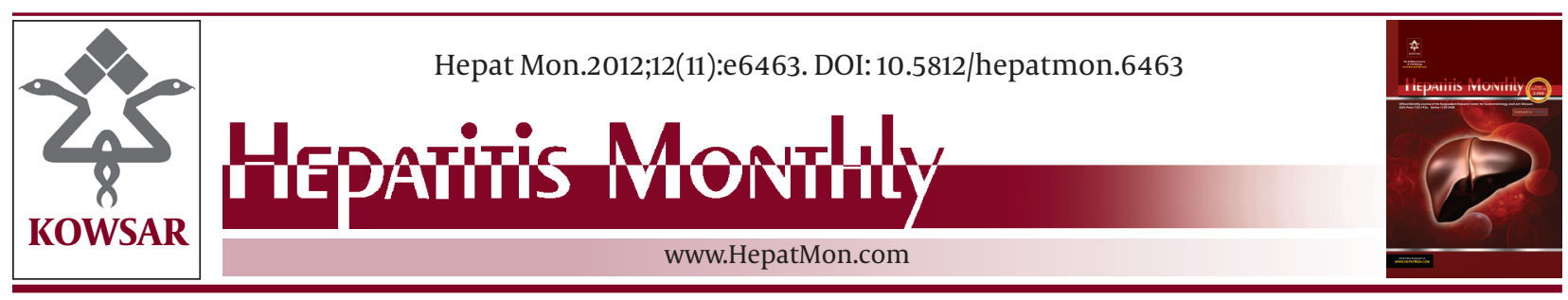

\title{
Reducing Social Disparity in Liver Transplantation Utilization through Governmental Financial Support
}

\author{
Kamran B. Lankarani ${ }^{1^{*}}$, Mojtaba Mahmoodi ${ }^{1}$, Siavash Gholami ${ }^{2}$, Soheila Mehravar ${ }^{1,3}$, Seyed \\ Ali Malekhosseini ${ }^{2}$, Sayed Taghi Heydari ${ }^{4}$, Elham Zarei ${ }^{1,3}$, Heshmatollah Salahi ${ }^{2}$, Saman \\ Nikeghbalian ${ }^{2}$, Seyed Alireza Taghavi ${ }^{5}$, Parisa Janghorban ${ }^{2}$, Fariborz Ghaffarpasand ${ }^{1}$ \\ ${ }^{1}$ Health Policy Research Center, Shiraz University of Medical Sciences, Shiraz, IR Iran \\ ${ }^{2}$ Shiraz Organ Transplantation Center, Shiraz University of Medical Sciences, Shiraz, IR Iran \\ ${ }^{3}$ Student Research Committee, Shiraz University of Medical Sciences, Shiraz, IR Iran \\ ${ }^{4}$ School of Medicine, Jahrom University of Medical Sciences, Jahram, IR Iran \\ ${ }^{5}$ Gastroenterology and Haepatology Research Center, Namazi Hospital, School of Medicine, Shiraz University of Medical Sciences, Shiraz, IR Iran
}

A R T I C L E I N F O

Article type:

Original Article

Article history:

Received: 05 May 2012

Revised: 25 May 2012

Accepted: 15 Jun 2012

Keywords:

Liver Transplantation

Financial Support

Iran

\begin{abstract}
A B S T R A C T
Background: A high proportion of patients suffering from end stage liver disease are from low socioeconomic classes, which limits their access to liver transplantation as the most effctive treatment of this condition because of cost barrier.

Objectives: one of the most challenging aspects of liver transplantation is its affordability and utilization by those who need it the most.

Patients and Methods: Since November 2005, Iran Ministry of Health had covered 100\% of the costs of in-patient liver transplantation care. To determine the effects of this policy, patterns of utilization of liver transplantation were compared before and after implementation of the policy. Group one included 112 and group two included 120 individuals who received transplantation before (from early January 2003 to November 2005) and after (from November 2005 to the end of December 2007) the legislation entered into the effect, respectively. Socioeconomic characteristics of these patients were evaluated by data collected about house and car ownership, education level, employment status, and place of residence.

Results: Coverage of the costs allowed more illiterate and semiliterate people $(P=0.032)$ as well as more unemployed or unskilled workers to receive transplantation $(P=0.021)$. The number of transplantations also increased in children and geriatric age group. This legislation also led to greater countrywide regional coverage of indigent patients.

Conclusions: This survey provides evidence that coverage of the costs by Ministry of Health was effective in reducing social discrimination in utilization of liver transplantation, and narrowed the gap between low and high socioeconomic classes in Iranian society.

Published by Kowsar Corp, 2012. cc 3.0.
\end{abstract}

- Implication for health policy/practice/research/medical education:

As many of patients suffering from end stage liver disease are from low socioeconomic classes subsidizing liver transplanataion which is currently the most effective treatment of this condition, would reduce the gaps in access and utilization of this treatment.

Please cite this paper as:

Lankarani KB, Mahmoodi M, Gholami S, Mehravar S, Malekhosseini SA, Heydari ST, et al. Reducing Social Disparity in Liver Transplantation Utilization through Governmental Financial Support. Hepat Mon. 2012;12(11): e6463. DOI: 10.5812/hepatmon.6463

${ }^{*}$ Corresponding author: Kamran B. Lankarani, Health Policy Research Center, Building No 2, Eighth Floor, School of Medicine, Zand Blvd., Shiraz University of Medical Sciences, Shiraz, IR Iran. Tel:+98-7112309615, Fax:+98-7112309615, E-mail: lanakaran@sums.ac.ir

DOI:10.5812/hepatmon.6463

Copyright@ 2012 Kowsar Corp. All rights reserved.

This is an Open Access article distributed under the terms of the Creative Commons Attribution License (http://creativecommons.org/licenses/by/3.0), which permits unrestricted use, distribution, and reproduction in any medium, provided the original work is properly cited. 


\section{Background}

Disparities in the utilization of health facilities and the ways to tackle them are of great interest to policy makers in the health care sector. Despite the aim to channel resources toward those in need, it is not uncommon to see more usage among high socioeconomic sectors of societies throughout the world (1-3). Research in this field, although necessary and interesting, is challenging because such studies will usually necessitate major changes in national health policies and budgets. Liver diseases constitute one of the major causes of mortality and morbidity in Iran (4). With an approximate carriage rate of 3\% for hepatitis B in middle age and elderly and a growing incidence of nonalcoholic steatohepatitis as well as increasing life expectancy, the number of people with chronic liver diseases is expected to rise in the future. According to a recent report by Iranian Ministry of Health, benign and malignant diseases of digestive tract and liver account for $8.3 \%$ of all non-accidental deaths, and next to cardiovascular diseases which are the leading cause of death (47\%). Moreover, the incidence of several liver diseases is rising (5). Liver transplantation is the only effective treatment for most patients with liver failure (6). Aside from the costs of post-operative care and transplant-related medication, liver transplantation per se is an expensive procedure. The mean cost of a liver transplant is about US\$163,438 (US\$145,277-181,598) in the United States and about US\$103,548 (US\$85,514-121,582) (7) in other member states of organization for economic cooperation and development (OECD) countries. At Shiraz Organ Transplantation Center this cost is estimated at approximately US $\$ 38,000$ (8). The relatively high number of patients in low-income sectors of society as well as high cost of the procedure itself my limit access of those with the greatest need to the procedure leading to potential social disparities in utilization of this treatment modality. The correlation between prevalence of chronic liver diseases and low socioeconomic status (SES) is well known (9). This factor is more prominent in developing countries where socioeconomic disparity restricts utilization of both traditional and modern health-care facilities in lower socioeconomic classes (10). In addition, compared to higher social classes, other risk factors of end-stage liver disease such as hepatitis B and C, and hepatocellular carcinoma are more prevalent in poor societies (11-13). Liver transplantation has been performed in the Islamic Republic of Iran since 1993. From 1993 to November 2005, the cost of liver transplantation was covered mostly by patients themselves. Starting from November 2005, Iranian Ministry of Health decided to cover $100 \%$ of the costs related to liver transplantation surgery. According to this new plan, , all surgery-related expenses were covered by the Ministry of Health for patients selected by transplant team based on clinical grounds. The organ allocation system was changed to the model for end-stage liver disease (MELD) scoring system 1.5 years before this legislation. Previously, a combination of the united network for organ sharing (UNOS) and child-turcotte-pugh (CTP) scoring system was employed to select patients for this procedure.

\section{Objectives}

In this study we compared socioeconomic characteristics of patients treated by liver transplantation; also the number of procedures before and after government financial support was introduced. Effect of new legislation on geographic distribution of the patients was also evaluated.

\section{Patients and methods}

\subsection{Study Population and Protocol}

The study was performed as a pre- and post-intervention face-to-face interview survey at Shiraz Organ Transplantation Center, Namazi Hospital, Shiraz University of Medical Sciences, Shiraz, Iran between September and December 2010. Approval was obtained from the institutional review board and ethics committee of Shiraz University of Medical Sciences before starting the study. All participants and/ or their parents submitted their written informed consent. Individuals who consented were interviewed personally. Answering to all or any of the questions was optional for all participants. We used a convenience sampling method with participants drawn from all literate individuals who agreed to participate in this study. The questions were asked during face-to-face interviews in Persian language. The interviewer intervened only to clarify a question if required. No attempt was made to lead the respondents by suggesting answers in any manner. A total of 232 patients participated, and were divided in two groups. Group one included 112 and group two included 120 individuals who received transplantation before (from early January 2003 to November 2005) and after (from November 2005 to the end of December 2007) the legislation came into force, respectively. The only exclusion criterion was refusal of patient to participate in the study.

\subsection{Data Collection Form}

Socioeconomic characteristics of the participants were recorded on a data collection form with items for house and car ownership (as proxies for income), level of education, employment status, and place of residence. All questions were open-ended with options for multiple responses.

\subsection{Statistical Analysis}

All data are reported as proportions or the mean \pm SD for $95 \%$ confidence intervals. Independent t-tests were applied to compare quantitative variables between the groups. The chi-squared test or Fisher's exact test was used to compare qualitative variables such as employment, sex, etc. A $P$ value less than 0.05 was considered statistically significant. 


\section{Results}

A total of 232 recipients were enrolled in two groups. In group one, 71 (64\%) and in group two, 81 (67.5\%) participants were female. After the law came into force, the number of transplantations performed per year increased dramatically (Figure 1). Although there was no substantial difference in the mean age of recipients before (33.5 \pm 14.4 years $)$ and after ( $30.3 \pm 16.15$ years) implementation of government law covering full costs of the procedure, the age distribution was changed (Figure 2). In group two, more patients in pediatric and geriatric age categories received liver transplants compared to group one, in which more middle-aged patients underwent transplantation. The two most commonly identified causes of end-stage liver disease in both groups were hepatitis B infection and autoimmune hepatitis (Table 1). Ascites in group one and jaundice in group two were the most common major complications. There were significant reductions in variceal bleeding, spontaneous bacterial peritonitis, and hepatic encephalopathy after commencement the law. However, appearance of jaundice as the most frequent complication of cirrhosis increased significantly (Table 2). After the beginning of ministerial coverage of transplantation costs, more illiterate and semiliterate people $(P=0.032)$ as well as more unemployed or unskilled workers received transplantation $(P=0.021)$. On the other hand, the proportion of participants who owned a house or a car increased slightly (Table 3). Assessment of geographical distribution in transplant recipients showed a greater achievement of regional coverage in group two (Figure 3). In place of resi-

\begin{tabular}{|c|c|c|c|}
\hline & Group 1 ${ }^{\mathrm{a}}$, No. (\%) (2003-2005) & Group $2^{b}$, No. (\%) (2005-2007) & P value \\
\hline HBV infection & $26(23.2)$ & $21(17.5)$ & 0.114 \\
\hline HCV infection & $6(5.4)$ & $4(3.3)$ & 0.534 \\
\hline HCC & $0(0)$ & $8(6.7)$ & $0.022^{c}$ \\
\hline Fulminant hepatitis & $1(0.9)$ & $1(0.8)$ & 0.999 \\
\hline AIH & $19(17)$ & $19(15.8)$ & 0.999 \\
\hline PBC & $1(0.9)$ & $1(0.8)$ & 0.999 \\
\hline PSC & $16(14.3)$ & $8(6.7)$ & $0.016^{c}$ \\
\hline Crigler-Najjar syndrome & $0(0)$ & $7(5.9)$ & $0.044^{\mathrm{c}}$ \\
\hline Budd-Chiari syndrome & $0(0)$ & $11(9.2)$ & $0.003^{\mathrm{c}}$ \\
\hline \multicolumn{4}{|c|}{ Inherited metabolic liver diseases } \\
\hline Tyrosinemia & $0(0)$ & $6(5)$ & $0.042^{\mathrm{c}}$ \\
\hline Wilson disease & $11(9.9)$ & $9(7.5)$ & 0.360 \\
\hline Hemochromatosis & $0(0)$ & $1(0.8)$ & 0.999 \\
\hline Alcoholism & $2(1.8)$ & $1(0.8)$ & 0.574 \\
\hline Biliary atresia & $4(3.6)$ & $4(3.3)$ & 0.999 \\
\hline CHF & $1(0.9)$ & $0(0)$ & 0.419 \\
\hline Caroli syndrome & $0(0)$ & $3(2.5)$ & 0.142 \\
\hline Byler disease & $2(1.8)$ & $3(2.5)$ & 0.362 \\
\hline Hypercholestrolemia & $0(0)$ & $3(2.5)$ & 0.267 \\
\hline Cryptogenic cirrhosis & $22(19.6)$ & $5(4.2)$ & 0.291 \\
\hline \multicolumn{4}{|l|}{ Overlap syndrome } \\
\hline $\mathrm{AIH}+\mathrm{PSC}$ & $0(0)$ & $2(1.7)$ & 0.267 \\
\hline \multicolumn{4}{|l|}{ Combined diseases } \\
\hline $\mathrm{HBV}+\mathrm{PBC}$ & $0(0)$ & $1(0.8)$ & 0.999 \\
\hline $\mathrm{HBV}+\mathrm{HCV}$ & $1(0.9)$ & $2(1.7)$ & 0.267 \\
\hline
\end{tabular}

Abbreviations: AIH, autoimmune hepatitis; CHF, congenital hepatic fibrosis; HBV, hepatitis B virus; HCC, hepatocellular carcinoma; HCV, hepatitis C virus; PBC, primary biliary cirrhosis; PSC, primary sclerosing cholangitis

a Individuals who received transplantation after the new legislation

$\mathrm{b}$ Individuals who received transplantation before the new legislation

c Significant difference $(P<0.05)$ 


\begin{tabular}{|c|c|c|c|}
\hline & Group 1 $^{\text {a }}$, No. (\%) (2003-2005) & Group $2{ }^{b}$, No. (\%) (2005-2007) & Pvalue \\
\hline Jaundice & $37(33.3)$ & $115(74.7)$ & $<0.001^{\mathrm{c}}$ \\
\hline Hepatic encephalopathy & $15(13.5)$ & $6(3.9)$ & $0.005^{c}$ \\
\hline Variceal bleeding & $17(15.3)$ & $4(2.6)$ & $<0.001^{\mathrm{c}}$ \\
\hline Ascites & $71(64)$ & $38(36)$ & $<0.001^{c}$ \\
\hline SBP & $6(5.4)$ & $2(1.3)$ & 0.072 \\
\hline Pulmonary hepatic failure & $0(0)$ & $2(1.3)$ & 0.511 \\
\hline
\end{tabular}

Abbreviation: SBP, spontaneous bacterial peritonitis

a Individuals who received transplantation before the new legislation

${ }^{\mathrm{b}}$ Individuals who received transplantation after the new legislation

${ }^{\mathrm{c}}$ Significant difference $(P<0.05)$

\begin{tabular}{|c|c|c|c|}
\hline & Group 1 ${ }^{\text {a }}$, No. (\%) (2003-2005) & Group $2^{\text {b }}$, No. $(\%)(2005-2007)$ & P value \\
\hline \multicolumn{4}{|l|}{ Dwelling } \\
\hline Rented & $20(18.2)$ & $18(15)$ & 0.874 \\
\hline Owned & $90(81.8)$ & $102(85)$ & 0.874 \\
\hline \multicolumn{4}{|l|}{ Car ownership } \\
\hline Yes & $36(31.9)$ & $39(32.8)$ & 0.357 \\
\hline No & $77(68.1)$ & $80(67.7)$ & 0.357 \\
\hline \multicolumn{4}{|l|}{ Occupation } \\
\hline Unemployed & $5(4.4)$ & $24(20)$ & $0.021^{c}$ \\
\hline Farmer, gardener or unskilled worker & $8(7.1)$ & $29(24.1)$ & $0.021^{c}$ \\
\hline Teacher, professor or clerk & $28(25)$ & $23(19.1)$ & $0.021^{c}$ \\
\hline Shopkeeper or merchant & $22(19.6)$ & $8(6.7)$ & $0.021^{c}$ \\
\hline Student & $24(21.4)$ & $12(10)$ & $0.021^{c}$ \\
\hline Housekeeper & $25(22.3)$ & $24(20)$ & $0.021^{\mathrm{c}}$ \\
\hline \multicolumn{4}{|l|}{ Education } \\
\hline Illiterate & $5(4.4)$ & $24(20)$ & $0.032^{c}$ \\
\hline Semiliterate & $4(3.5)$ & $54(45)$ & $0.032^{c}$ \\
\hline High school graduate & $66(58.9)$ & $32(26.7)$ & $0.032^{c}$ \\
\hline University degree & $37(33)$ & $10(8.3)$ & $0.032^{c}$ \\
\hline \multicolumn{4}{|l|}{ Area of residence (Rural or urban) } \\
\hline Seven largest cities & $70(62.5)$ & $31(25.8)$ & 0.058 \\
\hline Other provincial capitals & $12(10.7)$ & $31(25.8)$ & 0.058 \\
\hline Small cities or rural areas & $30(26.8)$ & $58(48.4)$ & 0.058 \\
\hline
\end{tabular}

dence terms, total number (30 in group one, 58 in group two) and variety of non-capital cities (18 in group one, 42 in group two) were increased in both groups.

\section{Discussion}

Among non-communicable diseases, end-stage liver disease is one of the most important causes of death. In the last decade Iran has achieved great advances in extending access to liver transplantation facilities (14). Liver transplantation is a costly procedure which imposes a heavy economic burden on either recipients or governments as a health provider (15). Growing social inequities in health status in developing and developed countries, together with increasing inequities in income and wealth, draw 


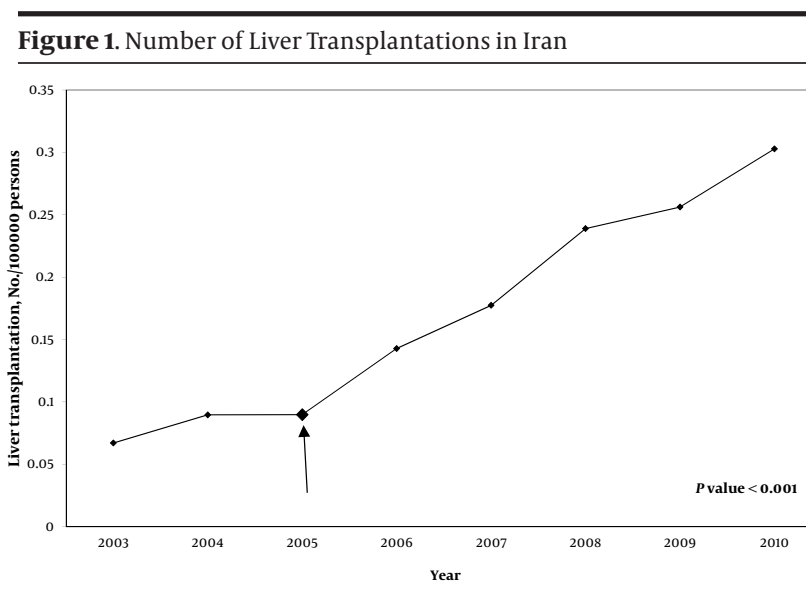

Total number of liver transplantations performed at Shiraz Organ Transplantation Center per year from 2003 to $2010(n=1028)$. The arrow indicates starting time of governmental financial support covering $100 \%$ of the cost of transplantation.

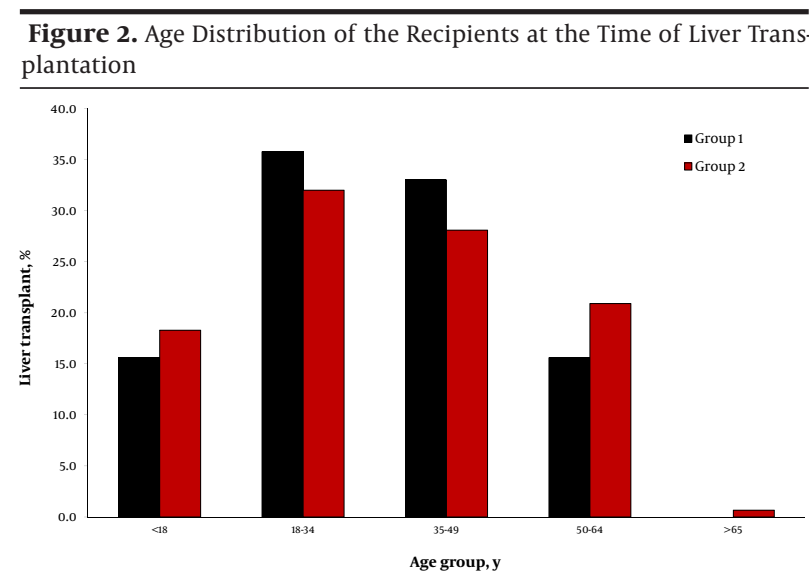

Age distribution of the recipients before (Group 1) and after(Group 2) governmental financial support.

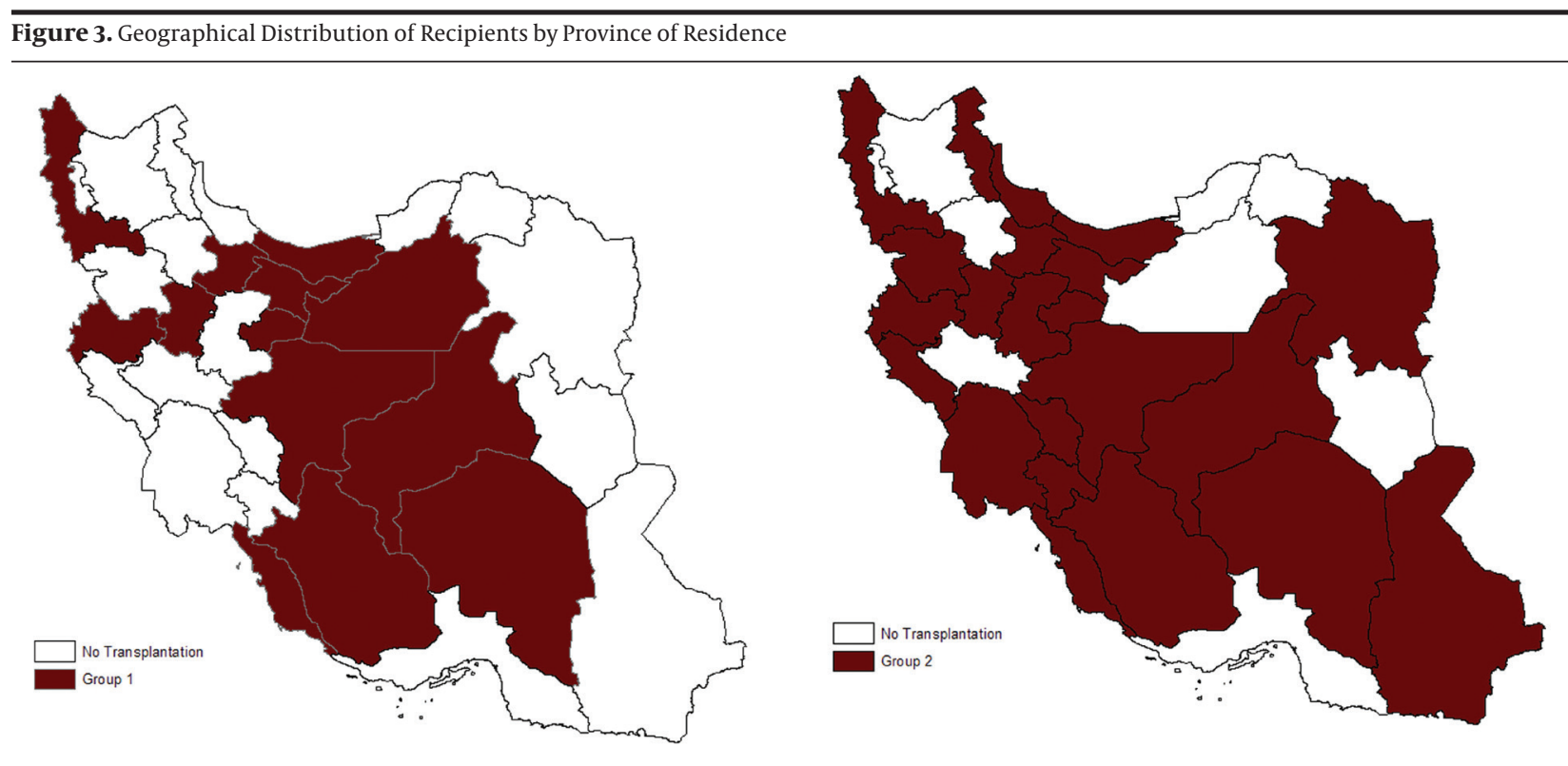

Geographical distribution of recipients before (Group 1) and after (Group 2) governmental financial support for liver transplantation

attention to socioeconomic class as a key determinant of accessibility and utilization of health care facilities $(10,16)$. The terms "socioeconomic status", "socioeconomic position" and "social class" are extensively used in health research, indicating widespread although often implicit recognition of the importance of socioeconomic factors for different health outcomes and estimations $(17,18)$. However, social class is a complex entity to measure. A number of factors are used as surrogate markers for social class, such as neighborhood income, insurance and education (19). In the United States of America, neighborhood income is used as a surrogate marker of actual income since disposable income for people with certain income levels can be limited because of property values (16). Reliable information on actual or estimated income is difficult to be obtained in Iran. Most people prefer to avoid talking about their salary or other income resources. Perhaps education, occupation, and house ownership are the best surrogate indicators of socioeconomic status in Iran. Our findings clearly indicate that the introduction of governmental financial support led to selection of more illiterate and semiliterate people as well as unemployed or unskilled workers for coverage of liver transplantation. These groups are among those who are most likely to be discriminated during the 
selection process. The same may occur in elderly and pediatric age groups, who were received more transplants after financial support program, too. Both these age groups are widely known to be vulnerable to discrimination.

Geographic location (metropolitan versus small cities, urban versus rural) is also one of the factors that may lead to discrimination in the allocation of organs for transplantation. This factor not only affects patients' access to healthcare facilities, but may also be an indirect indicator of social class. We showed that after commencement of financial aid program, more patients from small cities and rural areas received liver transplantation (Table 3). Furthermore, cases from more diverse areas of the country were selected for liver transplantation (Figure 3). Another result that is worth attention is the fact that after financial intervention, clinical presentation of transplantation candidates at the time of selection shifted from more serious and life-threatening conditions (variceal bleedings, hepatic encephalopathy) to less serious ones (jaundice). This may be the result of increased number of transplantations which made the selection of patients with less severe liver disease possible in conjunction with those who suffer from more advanced disease. Some surveys have considered social disparity in the context of liver transplantations with regard to different aspects such as racial and insurance disparities (20), racial disparities in transplantations for hepatitis B (21), disparities among blacks and whites (22), and disparities related to hepatocellular carcinoma (23). To date, however, it appears that no comprehensive studies focused on the utilization of liver transplantation facilities by high and low socioeconomic classes. The approach used for socioeconomic evaluation in our analysis might be a potential limitation. However, it should be emphasized that accurate determination of $g$ socioeconomic status in developing countries such as Iran is not an easy task. For example, Yoo et al. (24) applied Hollingshead Index of Social Status to identify and quantify socioeconomic status. But this classification, which is based on education and occupation, is not completely applicable in Iran, and its validity, reliability, and efficacy could not be verified with translated version of this index. Another way to evaluate SES used by Yoo et al. (25) was based on neighborhood income, education, and insurance. This way is not practical in Iran because of absence of zip codes, considered as a reliable source of information for median income. We therefore concluded that it was necessary to apply available measures and variables in Iran which are reliable in terms of information they provide.

Lack of long-term follow-up of patients was another limitation of our survey. One of the most important aspects of a postoperative course in recipients of liver transplant is their survival. Nonetheless, the impact of SES on survival remains controversial. As access to liver transplantation increases, additional researches in regard to long-term follow-up will be needed to assess whether financial support such as that provided by current Iranian system has any impact on long term survival of patients with low SES and end stage liver disease. In Iran before governmental sponsorship, patients had to pay costs of surgery from their own pocket, except very few cases whom were covered by semi-private insurances. After availability of governmentmandated coverage, all patients had the same access to liver transplantation facilities. As a result of rising number of liver transplantations, Ministry of Health was obliged to support higher costs of post-transplantation medication. Government subsidies and insured medication costs led to dramatic decreases in the costs of drugs. Through such financial support complex, patients now pay only $3 \%$ to $5 \%$ of total post-transplantation medication value. Our experience showed that provided financial support has been effective in reducing social discrimination in utilization of liver transplantation, and has narrowed the gap between low and high socioeconomic classes in Iran. We also showed that the total number of transplantations and access across the entire population of the country increased after public financial support became mandatory.

\section{Acknowledgments}

The authors wish to thank all the patients and their families who participated in this study. We express our sincere gratitude to all the staff members of Shiraz Organ Transplantation Center and the Liver Transplantation Coordination Unit for their kind cooperation. We also thank K. Shashok (Author AID in the Eastern Mediterranean) for improving the use of English in the manuscript.

\section{Authors' Contribution}

Kamran B. Lankarani contributed to study design, develop the concept, editing the manuscript and data collection; Mojtaba Mahmoodi contributed to study design, develop the concept, writing the manuscript and data collection; Siavash Gholami contributed to data collection; Soheila Mehravar contributed to data collection; Seyed Ali Malekhosseini contributed to develop the concept; Sayed Taghi Heydari contributed to data collection and analysis; Elham Zarei contributed to data collection; Heshmatollah Salahi contributed to data collection; Saman Nikeghbalian contributed to data collection; Seyed Alireza Taghavi contributed to design of the study; Parisa Janghorban contributed to data collection; Fariborz Ghaffarpasand contributed to study design and editing the manuscript.

\section{Financial Disclosure}

This project was financially supported by the Health Policy Research Center, Shiraz University of Medical sciences, Shiraz, Iran. Kamran B Lankarani was the minister of health form 2005 till 2009.Others declare no conflict of interest. 


\section{Funding Support}

This project was financially supported by the Health Policy Research Center, Shiraz University of Medical sciences, Shiraz, Iran.

\section{References}

1. Anderson NB. Solving the puzzle of socioeconomic status and health: the need for integrated, multilevel, interdisciplinary research. Ann NYAcad Sci.1999;896:302-12.

2. Butkus DE, Dottes AL, Meydrech EF, Barber WH. Effect of poverty and other socioeconomic variables on renal allograft survival. Transplantation. 2001;72(2):261-6.

3. Williams DR, Mohammed SA, Leavell J, Collins C. Race, socioeconomic status, and health: complexities, ongoing challenges, and research opportunities. Ann NYAcad Sci. 2010;1186:69-101.

4. Malekzadeh R, Dehpour AR. Report from Iran. Liver Int. 2008;28(8):1136-9.

5. Malek-Hosseini SA, Salahi H, Lahsai M, Bahador A, Bagheri-Lankarani K, Fattahi MR, et al. The first report of liver transplantation in Iran. Arch Iran Med. 2002;5:213-5.

6. Malek-Hosseini SA, Mehdizadeh AR, Salahi H, Saberi-Firouzi M, Bagheri-Lankarani K, Bahador A, et al. Results of liver transplantation: analysis of 140 cases at a single center. Transplant Proc. 2005;37(7):3157-8.

7. van der Hilst CS, Ijtsma AJ, Slooff MJ, Tenvergert EM. Cost of liver transplantation: a systematic review and meta-analysis comparing the United States with other OECD countries. Med Care Res Rev. 2009;66(1):3-22.

8. Mehdizadeh A, Fazelzadeh A. Life in death: an overview of solid organ transplant in Shiraz, Iran. Exp Clin Transplant. 2007;5(2):701-7.

9. Singh GK, Hoyert DL. Social epidemiology of chronic liver disease and cirrhosis mortality in the United States, 1935-1997: trends and differentials by ethnicity, socioeconomic status, and alcohol consumption. Hum Biol. 2000;72(5):801-20.

10. Braveman PA, Cubbin C, Egerter S, Chideya S, Marchi KS, Metzler M, et al. Socioeconomic status in health research: one size does not fit all.JAMA. 2005;294(22):2879-88.

11. Artinyan A, Mailey B, Sanchez-Luege N, Khalili J, Sun CL, Bhatia S, et al. Race, ethnicity, and socioeconomic status influence the survival of patients with hepatocellular carcinoma in the United States. Cancer. 2010;116(5):1367-77.
12. Meffre C, Le Strat Y, Delarocque-Astagneau E, Dubois F, Antona $D$, Lemasson JM, et al. Prevalence of hepatitis B and hepatitis C virus infections in France in 2004: social factors are important predictors after adjusting for known risk factors. J Med Virol. 2010;82(4):546-55.

13. Stuver SO, Boschi-Pinto C, Trichopoulos D. Infection with hepatitis B and C viruses, social class and cancer. IARC Sci Publ.1997;(138):31924.

14. Ghods AJ, Mahdavi M. Organ transplantation in Iran. Saudi J Kidney Dis Transpl. 2007;18(4):648-55.

15. Klarenbach S, Garg AX, Vlaicu S. Living organ donors face financial barriers: a national reimbursement policy is needed. CMAJ. 2006;174(6):797-8.

16. Krieger N, Williams DR, Moss NE. Measuring social class in US public health research: concepts, methodologies, and guidelines. Annu Rev Public Health. 1997;18:341-78.

17. Shavers VL. Measurement of socioeconomic status in health disparities research.J Natl Med Assoc. 2007;99(9):1013-23.

18. Uher R, Dragomirecka E, Papezova H, Pavlova B. Use of socioeconomic status in health research. JAMA. 2006;295(15):1770; author reply

19. Fein O. The influence of social class on health status: American and British research on health inequalities. J Gen Intern Med. 1995;10(10):577-86.

20. Yu JC, Neugut AI, Wang S, Jacobson JS, Ferrante L, Khungar V, et al. Racial and insurance disparities in the receipt of transplant among patients with hepatocellular carcinoma. Cancer. 2010;116(7):1801-9.

21. Howell CD. Racial disparities in liver transplantation for hepatitis B: to be or not to be. Liver Transpl. 2009;15(9):1007-9.

22. Reid AE, Resnick M, Chang Y, Buerstatte N, Weissman JS. Disparity in use of orthotopic liver transplantation among blacks and whites. Liver Transpl. 2004;10(7):834-41.

23. Robbins AS, Daily MF, Aoki CA, Chen MS, Jr., Troppmann C, Perez RV. Decreasing disparity in liver transplantation among white and Asian patients with hepatocellular carcinoma : California, 19982005. Cancer. 2008;113(8):2173-9.

24. Yoo HY, Galabova V, Edwin D, Thuluvath PJ. Socioeconomic status does not affect the outcome of liver transplantation. Liver Transpl. 2002;8(12):1133-7.

25. Yoo HY, Thuluvath PJ. Outcome of liver transplantation in adult recipients: influence of neighborhood income, education, and insurance. Liver Transpl. 2004;10(2):235-43. 